\title{
O Problema do Colonialismo na Era dos Museus Hiperconectados ${ }^{1}$
}

\author{
El Problema del Colonialismo nn la Era de los Museos Hiperconectados
} The Problem of Colonialims in the Era Of Hiperconected Museums

\author{
Lucas Monteiro de Araújo ${ }^{23}$ \\ Agenor Sarraf Pacheco ${ }^{4}$
}

\begin{abstract}
Resumo
As últimas décadas presenciaram mudanças ligeiras e exponenciais no campo tecnológico e comunicacional, com destaque para a criação da internet que ampliou e facilitou o acesso a informações em níveis globais. Frente a estas novas reconfigurações, os museus viram surgir uma ferramenta nova e aliada à disseminação de conhecimentos e interação com o público. Atualmente são poucas as instituições museológicas que não possuem website, as antigas cartas deram lugar a e-mails, catálogos deram lugar a coleções online, visitas virtuais, softwares de interação em tempo real, tudo possível de ser acessado em qualquer parte do mundo. $\mathrm{O}$ fato é que vivemos em uma era de museus hiperconectados - o próprio Conselho Internacional de Museus escolheu a hiperconectividade como temática para o dia dos Museus de 2018. Contudo, juntamente com estas novas perspectivas, também surgiram novos desafios e problemáticas, valendo destacar aqui a necessidade cada vez mais crescente de informações disponibilizadas pelas instituições museológicas. Este trabalho situa-se dentro deste debate, buscando problematizar o conteúdo veiculados por museus em suas plataformas digitais. Para tanto, tomamos para estudo o caso de coleções marajoaras digitalizadas e disponibilizadas nos sites de museus internacionais. Estas coleções são formadas principalmente por fragmentos cerâmicos, além de espécimes zoológicos e botânicos, cujas informações disponibilizadas se limitam a dados eminentemente técnico. Nossa compreensão é que esta forma de exposição revela um caráter colonialista dos museus, pois além de obscurecerem a "vida social" destes objetos, ainda reduz à cosmovisão dos grupos ali representados a números e medidas.
\end{abstract}

Palavras Chave: Museu; Coleções; Colonialismo.

\section{Resumen}

Las últimas décadas presenciaron cambios leves y exponenciales en el campo tecnológico y comunicacional, con destaque para la creación de internet que amplió y facilitó el acceso a informaciones a niveles globales. Frente a estas nuevas reconfiguraciones, los museos vieron surgir una herramienta nueva y aliada a la diseminación de conocimientos e interacción con el público. En la actualidad son pocas las instituciones museológicas que no poseen sitio web, las antiguas cartas dieron lugar a e-mails, catálogos dieron lugar a colecciones online, visitas virtuales, software de interacción en tiempo real, todo posible de ser accedido en cualquier parte del mundo. El hecho es que vivimos en una era de museos hiperconectados - el propio Consejo Internacional de Museos escogió la hiperconectividad como temática para el día de los Museos de 2018. Sin embargo, junto con estas nuevas perspectivas, también surgieron nuevos desafíos y problemáticas, destacando aquí necesidad cada vez

\footnotetext{
${ }^{1}$ Artigo apresentado no Simpósio Temático REPENSAR, REFLETIR, INTERPRETAR E REINTERPRETAR A MEMÓRIA, IDENTIDADE E O PATRIMÔNIO CULTURAL DA AMÉRICA COLONIAL durante o II Seminário Latino-Americano de Estudos em Cultura - SEMLACult em Foz do Iguaçu/PR, Brasil, 2018.

${ }^{2}$ Doutorando em Antropologia pelo Programa de Pós-Graduação em Antropologia da Universidade Federal do Pará; Belém, Pará, Brasil; araujo_lucas@outlook.com.

${ }^{3}$ O presente trabalho foi realizado com apoio da Coordenação de Aperfeiçoamento de Pessoal de Nível Superior - Brasil (CAPES) - Código de Financiamento 001.

${ }^{4}$ Doutor em História Social da Amazônia - Universidade Federal do Pará; Belém, Pará, Brasil; sarrafagenor@gmail.com.
} 
más creciente de informaciones disponibles por las instituciones museológicas. Este trabajo se sitúa dentro de este debate, buscando problematizar el contenido vehiculado por museos en sus plataformas digitales. Para ello, tomamos como estudio el caso de colecciones marajoaras digitalizadas y disponibles en los sitios de museos internacionales. Como mostraremos, estas colecciones están formadas principalmente por fragmentos cerámicos, además de especímenes zoológicos y botânicos, cuyas informaciones disponibles se limitan a datos eminentemente técnico. Nuestra comprensión es que esta forma de exposición revela un carácter colonialista de los museos, pues además de oscurecer la "vida social" de estos objetos, todavía reduce a la cosmovisión de los grupos allí representados a números y medidas.

Palabras Clave: Museo; Colecciones; Colonialismo

\begin{abstract}
The last decades saw slight and exponential changes in the technological and communicational field, with emphasis on the creation of the Internet, which expanded and facilitated the access to information at global scale. Faced with these new reconfigurations, the museums have seen a new tool emerging and an allied to the dissemination of knowledge and interaction with the public. At present there are few museological institutions that do not have a website, the old letters were substituted by e-mails, catalogs were replaced by online collections, virtual visits, real-time interaction softwares, all possible to be accessed anywhere in the world. The fact is that we live in an era of hyperconnected museums - the International Council of Museums itself chose hyperconnectivity as the theme for the 2018 Museum's Day. However, along with these new perspectives, new challenges and problems have also emerged, specially the growing need for information made available by museological institutions. This work is located within this debate, seeking to problematize the content communicated by museums in its digital platforms. To do so, we take to study the case of Marajoara collections digitized and made available on international museums websites. These collections are mainly made up of ceramic fragments, as well as zoological and botanical specimens, whose information is limited to eminently technical data. Our understanding is that this form of exhibition reveals a colonialist character of museums, because in addition to obscuring the "social life" of these objects, it still reduces the worldview of the groups represented there in numbers and measures.
\end{abstract}

Keywords: Museum; Collections; Colonialism

\title{
1. Introdução
}

Que nos últimos anos as novas tecnologias estão alterando definitivamente a forma como nos comunicamos é fato visível. Aplicativos de mensagens, e-mails, redes sociais, são suportes cada vez mais comuns no nosso dia a dia. As novas interações com as tecnologias afetam nossas formas de lidar com a informação, hoje disseminada e acessada facilmente em tempo real com um simples clique.

Neste cenário, os espaços museológicos também buscam adotar novos suportes tecnológicos como forma de divulgação de informações e conhecimentos. Atualmente são raros os museus que não possuem website, as antigas cartas deram lugar a e-mails, catálogos deram lugar a coleções online, visitas virtuais, softwares de interação com acervos, tudo possível de ser acessado de qualquer parte do mundo, vivemos o fenômeno chamado por Janaina Mello (2013) de cibercultura museal.

Contudo, a fácil difusão dos conhecimentos trouxe questionamentos sobre a qualidade da informação veiculada. No caso das redes sociais qualquer pessoa pode criar um boato, editar uma foto, forjar um vídeo e dissemina-los pelo globo. As assim chamadas 
fakenews estão cada vez mais comuns, não é à toa que grandes grupos de comunicação declararam guerra as notícias falsas e estão promovendo campanhas de conscientização de divulgação responsável de informações.

Da mesma forma, é necessário questionar a qualidade da informação repassada por instituições museológicas. Historicamente os museus, principalmente aqueles de cunho antropológico, vem sendo duramente criticados pelas formas como representam o Outro em seus espaços. A assim chamada crise dos museus que emergiu no período pós segunda guerra mundial levou profissionais das ciências humanas a repensarem o lugar deste Outro nas instituições museológicas, como bem aponta Montechiare (2015). Surgem, então, novas metodologias participativas ou cooperativas que, apesar de serem de caráter ainda experimental, buscam inserir agentes outros no processo de produção e disseminação de conhecimentos.

Por outro lado, apesar da existência destas novas abordagens, é possível ainda hoje verificar a reprodução de modelos colonialistas por parte de instituições museológicas, principalmente quando falamos do dito museu tradicional, que historicamente refletiu concepções etnocêntricas quando representam os Outros.

Assim, uma questão se impõe: na era dos museus hiperconectados, as instituições museológicas, ao adotarem novos suportes para a disseminação de informações, estão repensando seus discursos ou ainda continuam atreladas a visões colonialistas e reproduzindo visões etnocêntricas sobre os Outros?

Alfredo Wagner de Almeida, em trabalho recente, argumenta que os museus "consistem em produtos de relações sociais voltadas para uma multiplicidade de modos de colecionar objetos, de diferentes lugares e tempos históricos, e de exercer autoridade para classificá-los e exibi-los" (ALMEIDA, 2018, p. 47).

Pesquisas feitas pela American Aliance of Museums ${ }^{5}$ dos Estados Unidos concluíram que para mais de $98 \%$ dos norte-americanos os museus são locais de educação, sendo considerados fontes sobre informações históricas mais confiáveis que livros e professores. Para dar um exemplo brasileiro: José Ribamar Bessa Freire (2016) aponta que uma pesquisa realizada pelo Programa de Estudos dos Povos Indígenas da Faculdade de Educação da UERJ constatou que a imagem popularmente construída sobre populações indígenas nacionais é formatada a partir de influências da escola, dos museus e da mídia.

\footnotetext{
${ }^{5}$ Para mais informações sobre a pesquisa, vide https://www.aam-us.org/programs/about-museums/museumfacts-data/
} 
Todas estas informações corroboram com um fato: museus são instrumentos de poder. Eles colecionam, classificam, conservam, estudam, mas com destaque comunicam aquilo que consideram relevante. Neste sentido, Ka Tat Nixon Chen defende que os museus tem o poder de disciplinar mentalidades, nas suas palavras, "museums have the power to discipline the mindset of people by directing people to see what they should see and to know what they should know inside museums" (CHEN, 2013, p. 407).

O próprio Conselho Internacional de Museus - ICOM, reconhecendo esta faceta, defende em seu código de ética que "Os museus devem garantir que as informações que apresentam em suas mostras e exposições estejam bem fundamentadas, sejam precisas e levem em consideração os grupos ou crenças nelas representados” (ICOM, 2006, p. 30).

Por tudo acima exposto, defendemos que as informações veiculadas em museus devem ser constantemente revisitadas e atualizadas, de forma que consigam acompanhar as dinâmicas culturais e não produzam narrativas e visões estereotipadas e estáticas sobre os grupos ali representados em suas coleções.

É neste quadro que as novas tecnologias, com destaque para a internet, desempenham papel crucial, pois são a forma mais rápida e fácil de se acessar informações. Os sites de museu devem ser locais de acesso não somente para informações básicas das instituições (como horários de visitação, endereço, contato, etc.), mas também espaços educativos de disseminação de informações contextualizadas acerca das coleções.

No bojo destes debates, propomos analisar neste artigo conteúdos veiculados por museus em suas plataformas digitais, nomeadamente seus websites. Focaremos nossas atenções ao estudo das coleções marajoaras hoje guardadas em museus internacionais ${ }^{6}$ e que foram formadas por viajantes do século XIX. Mais especificamente, nossas analises são centradas nas bases de dados de duas instituições norte-americanas: o Museu Peabody de Arqueologia e Etnologia e Museu de Zoologia Comparada, ambas da Universidade de Harvard, nos Estados Unidos.

Estes Museus foram recebedores de coleções marajoaras formadas durante a expedição Thayer (1865-1866), chefiada pelo zoólogo suíço Louis Agassiz e sua esposa, a educadora norte-americana Elizabeth Agassiz. Lá estão guardados fragmentos cerâmicos, urnas, vasilhas, tangas, estatuetas, dentre outros, no caso do Museu Peabody, bem como uma série de espécimes zoológicos no caso do Museu de Zoologia Comparada. Buscamos mostrar que as informações disponibilizadas sobre estes artefatos se limitam a um caráter

\footnotetext{
${ }^{6}$ Limitamos este estudo aos museus internacionais, pois as instituições nacionais com coleções marajoaras do século XIX não possuem ainda base de dados online disponível para consulta.
} 
eminentemente técnico. Nossa compreensão é que esta forma de exposição revela o caráter colonialista por trás dos museus, pois além de obscurecerem a "vida social" (APPADURAI, 1986) destes objetos, ainda reduz à cosmovisão dos grupos ali representados a números e medidas.

\section{O Marajó dos Viajantes}

Para melhor desenvolvermos este trabalho, faz-se necessário breve apresentação da região sobre a qual falamos - o Arquipélago de Marajó - bem como o contexto que estavam inseridos os viajantes que por lá passaram no século XIX.

A região marajoara localiza-se no norte do Brasil, no estado do Pará, mais precisamente na foz do Rio Amazonas. No oitocentos, esta parte da Amazônia foi intensamente visitada e narrada por homens e mulheres das ciências que por lá passaram e registraram o que viram em diários, livros e artigos que hoje nos fornecem valiosas fontes para estudo da história social da região ${ }^{7}$.

Podemos destacar alguns fatores que contribuíram para a atração destes viajantes para lá: a) primeiramente por ser passagem obrigatória a todos aqueles que, partindo de Belém (capital do atual estado do Pará) desejavam alcançar o rio Amazonas - trajeto comum das expedições científicas. Circundar o arquipélago pelo lado norte significava passar pelo chamado Cabo Maguary, com águas turbulentas e risco de naufrágio. Assim sendo, a porção sul torna-se rota frequente, tomando os estreitos de Breves e o canal Tajapurú principalmente. Vilas como Breves e Gurupá são paradas estratégicas para as embarcações que reabasteciam os navios com madeira e apresentavam documentos no entreposto alfandegário no caso da última; b) em segundo lugar, o arquipélago também entra na rota das expedições por sua fauna e flora abundante, cenário almejado pelos viajantes para coleta de espécimes e formação de coleções, Ilha Mexiana e algumas fazendas locais como Juncal e Cajueiro são relatadas como centrais; c) por fim, mas não menos importante, as expedições científicas também singraram águas marajoaras na busca de sua famosa cerâmica arqueológica que no dezenove foi largamente explorada em sítios como o Pacoval, Teso dos Bichos, Santa Izabel e Camutins e enviada para museus internacionais e nacionais. Como aponta a arqueóloga Denise Schaan (2009, p. 108), "Desde que os sítios arqueológicos da Ilha de Marajó foram

\footnotetext{
${ }^{7}$ Em pesquisas realizadas no âmbito de um mestrado em Antropologia (ARAÚJO, 2017), estudamos os relatos de 33 homens e mulheres das ciências sobre a Amazônia Marajoara, tendo sido identificados pelo menos 56 livros (principalmente em português, inglês, francês, alemão, espanhol e italiano) escritos por eles e elas em que relatam suas experiências de pesquisa no arquipélago.
} 
descobertos, eles vêm sendo explorados para a coleta de objetos para museus. No século XIX, esse colecionismo confundia-se com a própria prática arqueológica".

Como resultado das expedições, temos hoje vastas coleções de materiais e espécimes marajoaras em museus europeus e norte-americanos, principalmente (SUANO, 1986). A formação destas coleções pode ser vista dentro de um quadro de mudança referencial, quando antigos dogmas teológicos dão lugar a estudos centrados em bases científicas sobre o homem e o mundo que o cerca. Estas mudanças emanam primeiramente a partir dos contatos estabelecidos desde as chamadas grandes navegações, momento em que o mundo europeu entrou em contato com universos radicalmente diferentes do seu, mas encontrando um importante ponto de inflexão nos séculos XVIII e XIX, quando ideais iluministas passaram a guiar o homem das ciências.

Neste contexto, os museus desempenharam papel central: em um primeiro momento através dos gabinetes de curiosidades, onde variados artefatos eram expostos sem uma organização ou sistematização lógica bem definida. Nestes espaços apresentar o que existia em terras distantes através de objetos não representava somente expor o novo, pessoas novas, curiosas, diferentes, mas também era uma forma de dominação, pois expunha igualmente o que valioso esses novos locais tinham. "Possuir exemplares do que existia em lugares tão longínquos, representava uma espécie de controle, poder e glória através do conhecimento" (POSAS, 2013, p. 163).

Por outro lado, no século XVIII e, principalmente, no XIX, surgem os museus científicos, caracterizados justamente pela busca de uma sistematização do conhecimento global a partir de uma matriz única de conhecimento, um "ponto zero", como defende Santiago Castro-Gómez (2005). Segundo Luciana Ballestrin,

O "ponto zero é um ponto de partida de observação, supostamente neutro e absoluto, no qual a linguagem cientifica desde o Iluminismo assume-se "como a mais perfeita de todas as linguagens humanas" e que reflete "a mais pura estrutura universal da razão" (Castro-Gomez, 2005c, p. 14). A lógica do "ponto zero" é eurocentrada e "presume a totalização da gnose ocidental, fundada no grego, no latim e nas seis línguas modernas imperiais europeias" (Mignolo, 2007b, p. 29) (BALLESTRIN, 2013, p. 104).

Essa busca por sistematizar o conhecimento levou a um exponencial aumento nas expedições científicas ao redor do globo. Viajantes naturalistas se lançavam por entre a realidade de um país registrando massivamente os mais variados aspectos. No caso marajoara, é na primeira metade do século XIX, por exemplo, que surgem os primeiros relatos sobre a cerâmica arqueológica da região. Segundo Denise Schaan (2012), é o viajante bávaro C. F. P. 
von Martius quem primeiro relata ter visitado o local chamado Camutins, no interior do Marajó, hoje um conhecido sítio arqueológico. Como ele, seguiram o naturalista mineiro Domingos Soares Ferreira Penna, o zoólogo suíço Louis Agassiz e sua esposa, a educadora norte-americana Elizabeth Agassiz, o geólogo canadense C. F. Hartt, o ornitólogo americano Joseph Beal Steere, dentre outros.

Os dados obtidos, bem com as coleções formadas, eram enviadas para museus e universidades nacionais e internacionais para estudos diversos acerca do homem e da natureza. Como resultado, houve neste momento um pulular de novas ideias e teorias sobre o mundo natural e social. É, por exemplo, neste período que Charles Darwin publica a primeira edição do seu famoso livro A Origem das Espécies (1859), anteriormente o botânico Carl Lineu já havia publicado o System Naturae (1735), ambas tentativas de apresentar o mundo a partir de uma base científica universalizante.

Dentro deste contexto de encontros surgem grandes e famosos museus científicos e antropológicos que conhecemos hoje. Nacionalmente, por exemplo, o Museus Nacional, no Rio de Janeiro, abriu as portas em 1818, sendo a primeira instituição museológica do Brasil; os esforços do naturalista Domingos Soares Ferreira Penna resultaram, em 1866, na criação do hoje Museu Paraense Emílio Goeldi, em Belém, no Pará; em São Paulo, já em finais do dezenove, é fundado o Museu Paulista (SCHWARCZ, 1993; GUALTIERI, 2008; LOPES, 2009; SANJAD, 2010).

A nível internacional, é criado em 1846, nos estados Unidos, o Instituto Smithsonian, atualmente o maior complexo de Museus científicos do mundo; também nos Estados Unidos é fundado, em 1866, o Museu Peabody de Arqueologia e Etnologia da Universidade de Harvard, um dos mais antigos daquele país devotado a Antropologia; na Europa é criado em 1862, na Alemanha, o hoje Museu Cinco Continentes cujas coleções são dedicadas a arte e cultura não-europeias. Estes são somente alguns exemplos que demonstram a grande expansão, até então sem precedentes, de museus científicos no mundo ocidental (LOPES, 2009).

Estas instituições foram recebedoras de grandes coleções de materiais variados formadas por homens e mulheres das ciências após viajarem por países distantes. Todavia, estes museus não serviam apenas como locais de guarda para as coleções, mas também como centros de produção e difusão de conhecimentos científicos sobre o mundo. Neste cenário, os museus de Antropologia foram especialmente importantes no processo de "invenção do Outro" (CASTRO-GÓMEZ, 2005). 
Representados a partir de sua cultura material, os grupos originários tinham suas vidas reduzidas a visões etnocêntricas firmadas em narrativas expositivas cuja formatação tomava como ponto regulador as nações imperiais europeias. Modos de vida e visões de mundo outras que não se alinhavam com uma normatização ocidental foram subalternizadas, exotizadas e marginalizadas. Teorias racialistas - como a do evolucionismo, darwinismo social e eugenia - encontraram eco nas instituições museológicas, cada vez mais especializadas na apresentação dos mundos selvagens.

As imagens e representações sobre o Outro forjadas nos museus resultavam no desenvolvimento de políticas reguladoras coloniais, pois davm legitimidade aos discursos da ciência moderna - não é à toa que um dos primeiros passos na consolidação da dominação colonial era justamente a criação de aparelhos estatais que legitimassem identidades colonizadas e colonizadoras (LOPES, 2009; BALLESTRIN, 2013). Santiago Castro-Gómez argumenta que

As taxonomias elaboradas pelas ciências sociais não se limitavam, assim, à elaboração de um sistema abstrato de regras chamado ciência, como ideologicamente pensavam os pais fundadores da sociologia, mas tinham consequências práticas na medida em que eram capazes de legitimar as políticas reguladoras do Estado (CASTRO-GÓMEZ, 2005, p. 80).

Em resumo, o fato é que os museus, através de suas exposições, se tornaram veículos de criação, reprodução e oficialização de um conhecimento ocidental letrado, científico, eurocêntrico e universalizante que ajuizava visões etnocêntricas sobre Outros localizados nas margens de um projeto moderno. Esta perspectiva se enquadra dentro do que Walter Mignolo (2007, p. 29) chamou de "diferença colonial”, ou seja, “[...] la exterioridad en el preciso sentido del afuera (bárbaro, colonial) construido por el adentro (civilizado, imperial)".

Críticas não foram poupadas às instituições museológicas no próprio século XIX vide por exemplo os trabalhos do antropólogo alemão Franz Boas -, bem como no decorrer do século XX. É, entretanto, no período pós-segunda guerra mundial que se estabelece nas ciências sociais um ponto de inflexão conformado a partir de um contexto social e político de descolonização de antigas colônias e emergência de novas potências, que levaram a uma fragilização de sistemas e paradigmas antes tidos como estáveis.

O modelo de museu etnográfico começa a ser questionado, principalmente por seu papel na construção da imagem do Outro. A Antropologia, disciplina gestada no ceio das instituições museológicas etnográficas do século XIX, agora é crítica do modelo e de suas formas eurocêntricas de representação. As censuras levaram os museus a repensarem suas 
coleções e estabelecerem diálogos mais abertos com a própria Antropologia e grupos originários. Na década de 1980 já é possível encontrar modelos de museus voltados muito mais para seu papel social, como no caso dos Ecomuseus, além de práticas colaborativas que buscam repensar ordens eminentemente técnicas nos fazeres museológicos.

Esses questionamentos ganharam eco com movimentos como o dos pós-coloniais e dos decoloniais, que buscam releituras das coleções e da própria história das instituições museológicas, objetivando desvelar histórias e resistências de um passado colonial escondido por trás dos objetos expostos.

É neste panorama que em finais da década de 1980 e início de 1990 surge a internet, meio que rapidamente se populariza e passa a ser adotado por museus no mundo todo como forma de divulgação de suas coleções e exposições. Obras são digitalizadas, informações sobre elas são disponibilizadas, catálogos de coleções online são criados e disponibilizados para consulta, até mesmo imersões em visitas online a exposições dos museus já são possíveis de serem feitas por qualquer pessoa com acesso à internet.

Esse processo de informatização representa, em nossa visão, uma excelente oportunidade para revisão das informações sobre peças, não basta somente copiar as informações que se tinha previamente e coloca-las online, é preciso questionar o que foi e está sendo dito sobre as peças e grupos originários nas bases de dados, caso contrário corre-se o risco de reprodução de discursos de poder.

\section{Hiperconectividade, Museus e Colonialismo}

Analisando de forma geral, o que os museus expõem são um conjunto de objetos que falam por pessoas, fora de seu contexto original e organizados de acordo com convenções metodológicas. Pensando no caso das peças marajoaras, quando retiradas de seu local de origem pelos viajantes do século XIX, elas eram colocados atrás de vitrines de grandes museus estrangeiros, passando a fazer parte de uma narrativa expositiva, em grande parte de caráter colonialista, através de um discurso erigido pela ciência moderna que refletia bases mentais com as quais eram traduzidas as diferenças percebidas entre povos das diversas partes do globo. No oitocentos este discurso frequentemente era aquele do evolucionismo, darwinismo social, eugenia, etc. Estas narrativas moldavam a percepção dos visitantes sobre os grupos ali expostos e oficializavam narrativas sobre esses Outros.

Em pesquisas recentes (ARAÚJO, 2017), percebemos que muitas das peças que ainda permanecem sob a guarda de instituições museológicas apresentam informações 
limitadas acerca de sua vida social antes de se tornarem parte de uma coleção de museu, modelo reproduzido quando da digitalização das peças para criação de sites e catálogos online. Na maioria dos casos estudados percebemos que são fornecidos nos websites dos museus somente dados eminentemente técnicos - como número de classificação, título da obra, descrição para inventário, departamento, proveniência, enfim, dados institucionais. Informações mais específicas são deixadas de lado, mas que são de fundamental importância para a compreensão não somente da vida social do objeto e do grupo por ele representado, mas também da própria história das instituições museológicas, de suas coleções e dos processos de musealização.

Thiago Oliveira, em trabalho sobre a cultura material, argumenta que

[...] a cultura material de populações tradicionais é constituída de objetos multireferenciados (Ribeiro, 1983, p. 12). Ou seja, objetos atravessados por práticas sociais que guardam conteúdos de ordem ecológica, econômica, técnica, estética, mítica, cosmológica, ritual e educativa, para citar apenas alguns campos. Isso significa que, por meio do estudo da cultura material, se pode alcançar inúmeros campos da vida social de uma determinada comunidade, uma vez que estes objetos possuem dimensões externas à sua própria materialidade, que com ela interagem de forma complexa e variável de sociedade para sociedade (OLIVEIRA, 2017, p. 173).

Apresentar informações majoritariamente técnicas sobre as peças em exposição reduz a visão de mundo dos grupos ali representados ao seu aspecto material. Em outros casos é apresentado somente o caráter utilitário do objeto, como se este fosse produzindo somente por necessidade utilitária, obscurecendo dimensões outras de grande importância para a compreensão da vida da peça. O fato é que, em muitos casos, "os museus [ainda] não sabem dimensionar a maneira de expor tais objetos" (FILHO E ATHIAS, 2016, p. 76).

Tomemos alguns exemplos para ajudar na reflexão. No século XIX a região de Breves era famosa por sua produção cerâmica. As peças eram produzidas no local por mulheres indígenas que residiam nas cercanias da vila, tendo motivos ornamentais, forma e técnica de produção ligeiramente diferentes da cerâmica arqueológica, tão famosa atualmente e que foi intensamente procurada por homens e mulheres das ciências no oitocentos.

Charles Frederick Hartt, geólogo canadense que passou por Breves na década de 1890, comenta que a vila "[...] talvez seja mais conhecida entre os viajantes por sua louça, sobrevivente de antiga indústria aborígene. Podem-se ahi comprar bacias, jarros, paliteiros, além de uma immensidade de ornamentos, em forma de pombas, tartarugas, jacarés, etc. etc." (HARTT, 1898, p. 174). Como fica claro por este, bem como por outros relatos de viajantes, existia uma indústria de produção de itens cerâmicos variados que eram vendidos aos viajantes e que dava fama a vila de Breves. Tal indústria se mantém principalmente no século 
XIX, mas decai e desaparece ainda em inicios do século XX e hoje é quase que inteiramente desconhecida quando comparada a fama das peças arqueológicas do arquipélago.

Um dos poucos e raros exemplares desta produção cerâmica que sobreviveu ao tempo está hoje guardado no Museu Peabody de Arqueologia e Etnologia da Universidade de Harvard, nos Estados Unidos. Esta peça foi coletada pelo zoólogo Louis Agassiz que juntamente com Elizabeth Agassiz, sua esposa, estiveram no Brasil entre os anos de 1865 e 1866, tendo passado por Breves nos dias 21 e 22 de agosto de 1865 . O casal relata sobre a compra da peça: "Depois de passar a vista por várias dessas cabanas, de comprar um ou dois macacos, alguns papagaios e alguns artigos da cerâmica da vila ${ }^{8}$ - tão feios quanto curiosos, diga-se a verdade - penetramos na floresta [...]" (AGASSIZ e AGASSIZ, 2000, p. 166).

Ao acessar a base de dados do Museu na busca por mais informações sobre a referida peça ${ }^{9}$ o quadro de informações que é mostrado expõe somente: número de controle da instituição, título para exposição, descrição para inventário, classificação, departamento, geografia/proveniência, materiais, dimensões, quantidade, doador e coletor. Ou seja, informações eminentemente técnicas e institucionais que falam muito mais para um público especializado e que omite toda e qualquer informação além do aspecto material.

Da mesma forma, as peças arqueológicas coletadas por Charles Frederick Hartt no arquipélago e preservadas na mesma instituição, apresentam informações resumidas, evidenciando um quadro que deixa a peça estática, congelada em uma página na internet, escondendo histórias de encontros, negociações e conflitos, silenciando vozes, usos, práticas cotidianas, cosmologias e modos de vida. Ocultar, propositalmente ou não, a vida social dos objetos cria uma narrativa unidirecional e impositiva por aqueles que tem o conhecimento dito especializado, direcionando olhares e naturalizando discursos de poder.

Neste sentido, Stuart Hall é esclarecedor ao analisar as formas como o velho mundo historicamente representou o novo mundo. Em suas palavras, a Europa

\footnotetext{
${ }^{8} \mathrm{Na}$ versão em português do livro do casal Agassiz publicada pela Livraria do senado, é dito somente "vaso" ao invés de "artigos da cerâmica da vila", contudo, na versão original em inglês o casal utiliza a frase "some articles of the village pottery", a palavra pottery pode ser entendida tanto como somente um utensílio (como um vaso), mas também como "cerâmica", no geral. Optamos por modificar a versão traduzida e utilizar "artigos de cerâmica da vila", pois entendemos esta visão define melhor o artesanato produzido em Breves, visto que não necessariamente eram somente vasos, mas também outros tipos de formas cerâmica, como ficou claro pelo excerto de C. F. Hartt anteriormente citado.

${ }^{9}$ Optamos por não reproduzir neste artigo imagens da peça nem do website do Museu, pois os mesmo são protegidos por direitos autorais. Para mais informações visitar: https://pmem.unix.fas.harvard.edu:8443/peabody/view/objects/asitem/search\$0040/2/titledesc?t:state:flow=236152c0-a05d-4e73-967f-5d1eb7d06dfb
} 
[...] usou suas próprias categorias culturais, idiomas, imagens e ideias para descrever e representar o Novo Mundo. Ela tentou inserir o Novo Mundo em abordagens conceituais já existentes, classificando-o de acordo com suas próprias normas e o incorporando a tradições ocidentais de representação. Isso não é novidade: frequentemente partimos do que já conhecemos para explicar e descrever o novo (HALL, 2016, p. 335- destaque nosso).

Acreditamos que os museus, ao adotarem modelos de representação com informações unicamente técnicas, sem uma contextualização do que se está expondo ou considerações sobre os pontos de vistas dos grupos originários (quando possível), estão ecoando colonialidades do poder e do saber nos processos de "invenção do outro" (CASTROGÓMES, 2005).

É justamente buscando desvelar esta dimensão social em que os objetos estão envolvidos que Berta Ribeiro e Lúcia Van Velthem (1992), defendem a aplicação da pesquisa contextual. Para elas, as coleções devem ser entendidas como dentro um sistema no qual o objeto "é parte integrante mas extravasa sua dimensão física" (RIBEIRO E VAN VELTHEM, 1992, p. 106). As autoras argumentam que

\footnotetext{
"A forma de comunicar toda a trama de interações que cerca um item da cultura material é contextualizá-lo. Com isso se entende a explicitação não só dos processos de manufatura, dos modos de uso, dos materiais constituintes, mas também das idéias e comportamentos associados" (RIBEIRO e VAN VELTHEM, 1992, p. 106).
}

A pesquisa contextual que assinalam Riberio e Van Velthem demonstra um passo na direção de uma apresentação menos arbitrária e mais compromissada com a realidade social do objeto. Entretanto, em muitos casos as peças são muito antigas ou os grupos originários podem já não existir mais ou ainda existir, mas não produzir mais artefatos similares. Este é o caso do exemplar sobrevivente da indústria cerâmica de Breves, cujo grupo indígena que a produzia já não existe mais.

Em situações dessa natureza, Ribeiro e Van Velthem defendem a pesquisa referencial. Nela, as coleções tem relação estreita com dados documentais que auxiliam no estudo dos objetos - como no caso dos livros, artigos e diários de viajantes, nos quais é possível o cruzamento de dados informados pelo próprio viajante com as coleções.

Vale aqui citar um exemplo que nos permite visualizar a aplicação da pesquisa referencial. A coleção zoológica formada durante expedição Thayer do casal Agassiz, está atualmente guardada no Museu de Zoologia Comparada da Universidade de Harvard nos Estados Unidos. 
Em 22 de agosto de 1865, quando de passagem pelo canal Tajapuru (que liga o rio Pará ao Rio Amazonas) na parte sul do Arquipélago de Marajó, lê-se o seguinte relato de Elizabeth Agassiz:

"Os índios daqui são muito destros em matéria de pescaria, e, em lugar de ir colecionar, Agassiz, mal chega a um lugar qualquer, contrata alguns pescadores e fica a bordo superintendendo os desenhos e a preparação dos exemplares à medida que vão chegando" (AGASSIZ e AGASSIZ, 2000, p. 170).

Mais além, em uma carta enviada por Louis Agassiz a seu amigo pessoal José Antônio Pimenta Bueno, um político brasileiro, datada também de 22 de agosto de 1865 "entre Tajapuru e Gurupá", lemos a seguinte passagem: "Infelizmente os índios compreenderam mal as nossas instruções e só nos trouxeram um único exemplar de cada espécie" (AGASSIZ e AGASSIZ, 2000, p. 168). Como fica claro pelas duas passagens, tanto Louis quanto Elizabeth não realizaram coletas - pelo menos não nesta parte da região marajoara -, mas sim contrataram indígenas para a realização tal tarefa enquanto eles ficavam organizando e preparando os primeiros registros de acordo com que os espécimes iam sendo trazidos pelos indígenas.

Contudo, ao recuperar os dados fornecidos no site do Museu de Zoologia Comparada referentes as coletas realizadas na região marajoara durante a expedição dos Agassiz, encontramos realidades que destoam das relatadas pelo próprio casal, como podemos ver no exemplo abaixo:

\begin{tabular}{|c|c|}
\hline \multicolumn{2}{|l|}{ Identifications } \\
\hline \multicolumn{2}{|c|}{ Ameiva ameiva ameiva (Linnaeus, 1758) } \\
\hline \multicolumn{2}{|c|}{$\begin{array}{l}\text { Animalia Chordata Reptilia Lepidosauromorpha Squamata Sauria Teiidae Ameiva ameiva ameiva } \\
\text { Identified by Catalog } \\
\text { Nature of ID: migration } \\
\text { Remarks: Catalog/1999 }\end{array}$} \\
\hline \multicolumn{2}{|c|}{ Locality and Collecting Event Details } \\
\hline Continent/Ocean: & South America \\
\hline Country: & Brazil \\
\hline State/Province: & Para ___________ \\
\hline Specific Locality: & Brazil,Para, Ilha de Marajo,Furo Tajapuru at Tajapuru \\
\hline Verbatim Locality: & Tajapura _ _ _ _ _ \\
\hline Collecting Source: & wild caught \\
\hline Coordinates: & $\begin{array}{l}-1.83333^{\circ}-50.41667^{\circ} \text { (Datum: WGS84), Error: } 11.865 \mathrm{~km} \\
\text { MCZ; 2003-12-16; Source: Alexandria Digital Library Gazetteer } \\
\text { Coordinate Remarks: used Furo do Tajapuru STMD, extent estimated to be } 9.25 \mathrm{~km}\end{array}$ \\
\hline Collecting Date: & [no verbatim date data] (1700-01-01-2100-01-01) \\
\hline \multicolumn{2}{|l|}{ Collectors } \\
\hline Louis Agassiz & \\
\hline
\end{tabular}

Figura 1 - Imagem da base de dados do Museu de Zoologia Comparada (destaque nosso) Fonte: https://mczbase.mcz.harvard.edu/guid/MCZ:Herp:R-3312 
Apesar da própria Elizabeth no livro, bem como Louis na carta enviada a Pimenta Bueno afirmarem que quem realizava as coletas eram os indígenas contratados, a informação de coleta que consta nas bases do Museu dão créditos somente ao viajante, silenciando a agencia de habitantes locais no próprio processo de construção da ciência moderna.

O fato é que estes viajantes do século XIX foram quase que inteiramente dependentes destes facilitadores locais, que além de informantes também coletavam e vendiam objetos e espécimes zoológicos aos homens e mulheres das ciências. Atualmente são reconhecidas estas interações por estudiosos das ciências que veem nelas o que chamam de ciência mestiça ou hibrida. Neil Safier comenta a este respeito:

"[...] historians of Science have come to recognize that knowledge acquired by European expeditions overseas included at least some portion of knowledge derived from indigenous sources and that in many cases imperiam recognessance depended entirely on these contacts with local culture. Historians and anthropologists have redefined scientific knowledge collected at the so-called "periphery" and processed at the imperial "center" in myriad ways, ranging from knowledge that is hybrid or "mestizo" in character to a kind of "middle-ground" knowledge" (SAFIER, 2010, p. 136).

Porém, este juízo não se traduz inteiramente no reconhecimento destes facilitadores como construtores da ciência moderna (como fica evidente no exemplo que demos acima), na realidade pouca atenção ainda é dada a estes agentes locais ou pior ainda, são completamente obscurecidas suas contribuições. Carey McCormack (2017, p. 111), argumenta que "While most historians of colonial botany acknowledge that botanists and natualists used local guides to collect specimens and indigenous information, they rarely accord these assistants more than cursory attentions".

Defendemos que o colonialismo museológico reside no silenciamento dessas interações locais em detrimento de informações que apenas colocam o viajante como coletor de determinado objeto ou espécime. Nesse caso, o que se este fazendo é nada mais do que reafirmar um discurso hegemônico que nega a agencia dos habitantes locais nas expedições científicas. Vale notar que mesmo quando da digitalização e informatização dos dados, não foram realizados estudos ou pesquisa documental que se aprofundassem na história do objeto, mas apenas a reprodução de um discurso construído ainda no século XIX.

Não buscamos com os exemplos que apresentamos e posições que assumimos, demonizar as pesquisas técnicas em torno das coleções, muito menos criticar o uso da internet ou a criação de coleções online para disponibilização de informações. Pelo contrário, cremos que estes são meios de fundamental importância para a democratização das instituições 
museológicas, bem como importantes fontes que permitem desvelar práticas e modos de vida de populações que habitaram a região marajoara em tempos passados.

O que de fato almejamos é mostrar que a forma como as peças tem sido apresentadas nas bases de dados reforçam imagens de poder ao se limitarem disponibilização de dados técnicos. Talvez devêssemos investir em práticas colaborativas, troca de informações, parcerias institucionais, intercâmbio de profissionais na tentativa de ampliar o olhar sobre estas coleções, bem como permitir ricos e fecundos encontros entre as peças e populações atuais cujas histórias de vida descendem daqueles grupos originários.

\section{Referências}

AGASSIZ, J. L. R.; AGASSIZ, E. C. Viagem ao Brasil 1865-1866. Brasília: Senado Federal, 2000 .

ALMEIDA, A. W. B; OLIVEIRA, M. A. (Org). Museus indígenas e quilombolas: centro de ciências e saberes. Manaus: UEA Edições/ PNCSA, 2017.

APPADURAI, A. The Social Life of Things: commodities in cultural perspective. Cambridge University Press, 1986.

ARAUJO, L. M. Representações Marajoaras Em Relatos De Viajantes: Natureza, Etnicidade e Modos de Vida no Século XIX. Universidade Federal do Pará, Programa de Pós-Graduação em Antropologia. Dissertação de Mestrado, 2017.

BALLESTRIN, L. América Latina e o giro decolonial. In. Revista Brasileira de Ciência Política, n. 11. Brasília, maio - agosto de 2013, pp. 89-117.

CASTRO-GOMEZ, S. Ciências sociais, violencia epistêmica e o problema da 'invenção do outro'. In. LANDER, Edgardo (org.). A colonialidade do saber: eurocentrismo e ciências sociais, perspectivas latino-americanas. Buenos Aires: Clacso, 2005.

CHEN, K. T. N. The Disciplinary Power of Museums. In. International Journal of Social Science and Humanity, v. 3, n. 4, Julho, 2013.

FILHO, M. L.; ATHIAS, R. Dos museus etnográficos às etnografias dos museus: o lugar da Antropologia na contemporaneidade. In. RIAL, C.; SCHWADE, E. (org.). Diálogos antropológicos contemporâneos. Rio de Janeiro: Associação Brasileira de Antropologia, 2016.

FREIRE, J. R. B. Museus indígenas, museus etnográficos e a representação dos índios no imaginário nacional: O que o museu tem a ver com educação? In. KURY, M. X. (Org). Museus e indígenas: saberes e ética, novos paradigmas em debate. São Paulo: Secretaria da Cultura : ACAM Portinari : Museu de Arqueologia e Etnologia da Universidade de São Paulo, 2016. 
GUALTIERI, R. C. E. Evolucionismo no Brasil: ciência e educação nos museus 1870-1915. São Paulo: Ed. Livraria da Física, 2008.

HALL, S. O ocidente e o resto, discurso e poder. Projeto História 56, 2016, pp. 314-361.

HARTT, C. F. A região de Breves. In. Boletim do Museu Paraense de Hist. Nat. e Etnog. Tomo II, Fascículos 1 -4. Belém: Typografia de Alfredo Silva \& Comp. 1898.

LOPES, M. M. J. R. O Brasil descobre a pesquisa científica: os museus e as ciências sociais no século XIX. São Paulo: Aderaldo \& Rothschild; Brasília, DF: Ed. da UNB, 2009.

MCCORMACK, Carey. Collection and Discovery: Indigenous Guides and Alfred Russel Wallace in Southeast Asia, 1854-1862. Journal of Indian Ocean World Studies, v. 1, 2017. pp 110-127.

MELLO, J. C. Museus e Ciberespaço: Novas Linguagens da Comunicação na Era Digital. In. Cultura Histórica \& Patrimônio. V. 1, n. 2, p. 6-29, 2013. ISSN 2316-5014. Disponível em:https://publicacoes.unifalmg.edu.br/revistas/index.php/cultura_historica_patrimonio/articl e/view/01_art_v1n2 Acesso em: 15 nov. 2018.

MIGNOLO, W. D. El Pensamiento Decolonial: Desprendimiento Y Apertura. In. CASTROGÓMEZ, S.; GROSFOGUEL, R. El giro decolonial: reflexiones para una diversidad epistémica más allá del capitalismo global. Bogotá: Siglo del Hombre Editores, 2007.

MONTECHIARE, R. Museu, objetos e os diferentes tempos confluentes. In. Novos Debates: Fórum de Debates em Antropologia. v. 2, n. 1, jan. 2015. Disponível em: http://novosdebates.abant.org.br/index.php/numeros-anteriores/v2n1 Acesso em: 15 nov. 2018.

OLIVEIRA, T. L. C. Artefatos para o ensino: a pesquisa por meio de práticas criativas com a cultura material. In. BELTRÃO, J. F.; LACERDA, P. M. Amazônias em tempos contemporâneos: entre diversidades e adversidades. Rio de Janeiro: Mórula, 2017.

POSAS, H. C. G, Classificar e ordenar: os gabinetes de curiosidades e a história natural. In. VIDAL, D. G. FIGUEIREDO, B. G. Museus: dos gabinetes de curiosidades à museologia moderna. [s.l.: s.n.], 2013.

RIBEIRO, G. B. VAN VELTHEM, L. H. Coleções Etnográficas: Documentos Materiais para a História Indígena e a Etnologia. In. CUNHA, M. C. SALZANO, F. M. (Orgs.). História dos Índios no Brasil. São Paulo, SP: Fundação de Amparo à Pesquisa do Estado de São Paulo, 1992.

SAFIER, Neil. Global Knowledge on the Move: Itineraries, Amerindian Narratives, and Deep Histories of Science. In. Isis, v. 101, p. 133-145, 2010.

SANJAD, N. A coruja de minerva: o museu paraense entre o Império e a República (18661907). Brasília: Instituto Brasileiro de Museus; Belém: Museu Paraense Emílio Goeldi; Rio de Janeiro: Fundação Oswaldo Cruz, 2010. 
SCHAAN, D. P. Cultura marajoara. Ed. trilíngüe. Rio de Janeiro, RJ : [Belém, Brazil]: Senac Editoras ; Federação de Comércio do Estado do Pará, Centro do Comércio do Pará, 2009.

. Entre a tradição e a pós-modernidade: a cerâmica marajoara como símbolo da identidade 'paraense'. In: MAUÉS, H. R. e MACIEL, M.E. (ed). Diálogos Antropológicos: diversidades, patrimônios, memórias. Belém: L \& A Editora, 2012. pp. 35-68.

SCHWARCZ, Lilia Moritz. O espetáculo das raças: cientistas, instituições e questão racial no Brasil, 1870-1930. São Paulo, SP: Companhia das Letras, 1993.

SUANO, M. O que é museu. São Paulo: Brasiliense, 1986. 